\title{
A severe thunderstorm climatology for Australia and associated thunderstorm environments
}

\author{
John T. Allen ${ }^{1}$, David J. Karoly ${ }^{1}$, Graham A. Mills ${ }^{2}$ \\ ${ }^{1}$ School of Earth Sciences, The University of Melbourne, \\ Melbourne, VIC, 3010, Australia \\ ${ }^{2}$ Formerly Centre for Australian Weather and Climate Research, \\ Melbourne, VIC, 3001, Australia
}

(Manuscript received May 2011; revised August 2011)

\begin{abstract}
Severe thunderstorms can present a significant threat to life and property in Australia. A unique and broad database of severe thunderstorm reports has been constructed for the Australian region for 2003-2010 from observer reports of hailstones, winds in excess of $90 \mathrm{~km} \mathrm{~h}^{-1}$ and, less frequently, tornadoes. Based on this database, a climatology of atmospheric environments associated with the occurrence of severe thunderstorms in Australia was developed using pseudo-proximity soundings from the MesoLAPS numerical weather prediction model simulations. Observed soundings have been used to verify derived soundings from MesoLAPS simulations, with a reasonable performance over much of the continent. Proximity rawinsonde soundings from the MesoLAPS simulations were identified for each of the severe thunderstorm reports to develop the climatology of environments. This climatology was then used to derive discriminants between environments with an increased likelihood of severe thunderstorm occurrence and other thunderstorm environments. This appears to be the best way to produce a long-term climatology of severe thunderstorm environment occurrence in a sparsely populated continent without considering the complex problem of initiation.
\end{abstract}

\section{Introduction}

Severe thunderstorms present a significant threat to life and property in Australia. Thunderstorms can produce large hailstones, damaging winds and less frequently tornadoes. Any of these phenomena can result in high-impact severe thunderstorm events. For example, a 1999 hailstorm in Sydney caused in excess of 1.5 billion dollars in damage (Yeo et al. 1999; Harper et al. 2001). This highlights the importance of understanding the ingredients in the atmosphere that are associated with severe thunderstorms, such as moist static instability and large shear of the horizontal wind. We refer to these as severe thunderstorm environments-environments with an increased likelihood for the occurrence of a severe thunderstorm based on the ingredients present.

Corresponding author address: John T. Allen, School of Earth Sciences, The University of Melbourne, Melbourne, VIC, 3010, Australia email: johnterrallen@gmail.com
A key issue when developing a climatology is whether a network of observers can produce an accurate spatial and temporal distribution of severe thunderstorm occurrence for a continental area. The motivation behind this climatology is simple; no current dataset or climatology for Australia offers sufficient resolution or geographic extent for planning purposes. Similarly, no long-term picture of the Australian severe thunderstorm environment yet exists. Previous studies have attempted to use observed proximity soundings based on the combination of thunderstorm reports and radiosonde data. However, the sparse nature of both sets of data has limited the usefulness of these climatologies. In Australia, the observations problem is particularly pronounced with a strong bias in the distribution of observers towards metropolitan areas and the coastal fringe over a relatively vast continental landmass. Alternative approaches to assessing severe thunderstorm frequency and distribution are to apply an ingredients-based methodology, or to consider synoptic patterns favorable to thunderstorm development and that 
provide initiation mechanisms. Owing to the difficulty of automated identification of when and where thunderstorms initiate using relatively coarse data, we consider the relatively simple and non-conditional environments in which severe thunderstorms have the potential to form. In this study, we approach this by deriving a set of environmental ingredients associated with reported severe thunderstorms. The environmental profiles are provided by an operational numerical weather prediction model, which is specifically configured to the Australian continent. The association between environmental ingredients and reports can be used to determine discriminants which separate environments that are likely to produce non-severe thunderstorms from those likely to produce severe thunderstorms. At a later stage, these discriminants can be used to estimate and evaluate the overall climatology of severe thunderstorm environments over longer periods than is otherwise available using direct consideration of severe thunderstorm reports.

To develop an ingredients-based climatology (applying the approach of Doswell et al. (1996)), a database of severe thunderstorm reports is required. In Australia, thunderstorms associated with any one or more of extreme rainfall, hail greater than $2 \mathrm{~cm}$, wind gusts in excess of 90 $\mathrm{km} \mathrm{h}^{-1}$ or any tornadic event are considered to be severe (Mills \& Colquhoun 1998). Two-tier classifications have also considered 'significant' severe weather in North America (Hales 1993), which has elevated thresholds based on extensive climatologies of severe thunderstorm reports (e.g. Kelly et al. (1985)). This however has little bearing on the damaging potential of events, as severe hail in Australia (which does not often exceed the $5 \mathrm{~cm}$ criterion for significant severe) still causes substantial damage to both properties and homes (Yeo et al. 1999; Harper et al. 2001). An ideal set of severe thunderstorm criteria would include the largest possible sample of events that cause substantial damage, while still providing a distinguishing set of thresholds. A further caveat is that little physical difference exists between a storm that produces near severe, and severe weather, and similarly between severe and significant severe weather (Doswell 2001). In order to balance the elevated thresholds of the significant severe criteria, both severe and significant severe reports are considered in this paper for application to the Australian climatology.

Reports of severe thunderstorm events in Australia are provided by a network of observers. Some of these observers are meteorologists by profession, and others volunteers with no formal meteorological training. These reports are dependent upon individuals distributed across a geographical area observing the meteorological phenomena and damage caused by a thunderstorm. This reliance on a network of observers with varied qualifications and experience means severe weather reports are subject to a number of variable factors (Kelly et al. 1985; Kuleshov et al. 2002; Doswell et al. 2005). The greater density of observers near population centres, and the sparse distribution of observers in less-populated rural areas has a significant impact on the quality of data obtained (Hales 1993; Doswell 2001; Griffiths et al. 1993). The areas of less dense population, combined with the relatively small areas damaged by severe thunderstorms, can mean many events go unreported (Kelly et al. 1985; Griffiths et al. 1993; Mills and Colquhoun 1998). Subject to the above limitations, climatologies thus far for Australia suggest that severe thunderstorms are most prevalent between October and April (Niall and Walsh 2005; Schuster et al. 2005; Kuleshov et al. 2002; Harper et al. 2001). In this study, the reports for the entire year were considered, before further filtering was applied upon identification of the climatological distribution. Given the observational limitations of severe thunderstorm reports in Australia, it is likely poor practice to represent the climatology of severe thunderstorms solely using these reports. Hence to identify the occurrence of these events, we consider an ingredients-based method. This allows us to consider the probability of occurrence of severe thunderstorms based on the environments in which they form, producing a more uniform distribution over the continent, controlled by the availability of the source dataset as opposed to the spatial population distribution.

In order to identify severe thunderstorm environments, a source of proximity environmental sampling is required. Rawinsonde proximity soundings have been extensively used both overseas (Brooks et al. 1994; Rasmussen and Blanchard 1998; Rasmussen 2003) and in Australia (Ryan 1992; Davis and Walsh 2008) to provide relationships between large-scale environmental conditions and thunderstorm occurrence. A problem with this type of approach is the sparse spatial distribution of rawinsonde stations relative to the location of recorded severe thunderstorms. Upperair soundings taken more than 200 kilometres away from a thunderstorm may not be representative of that storm's environment (Ryan 1992; Brooks et al. 1994; Potvin et al. 2010). The Australian rawinsonde network exceeds spatial distances of $200 \mathrm{~km}$ between sites in most cases (Ryan 1992). A second issue surrounds the timing of rawinsonde releases. Soundings in Australia are taken at 0000 GMT (10.00 am local time on the east coast), with a few locations recording at 1200 GMT (10.00 pm), neither of which are ideal for proximity soundings. This temporal proximity of a rawinsonde is important because advection processes and localised boundary effects can result in rapid modification of sounding environments (Potvin et al. 2010). The alternative to rawinsonde data is to use reanalysis or model-derived 'pseudo-proximity' soundings (Lee 2002), which use grid points in proximity to severe thunderstorm reports. This produces a vertical profile similar to those derived using observational soundings (Brooks and Dotzek 2006), albeit with reduced vertical resolution. However, some deviation (up to $500 \mathrm{~J} \mathrm{~kg}^{-1}$ ) exists in thermodynamic variables such as Convective Available Potential Energy (CAPE) determined in this way. These differences result from the limited vertical resolution of reanalyses, and variations in the representation of the boundary layer (Brooks et al. 2003, Thompson et al. 
2003, 2007). Additionally, a mixed-layer of near-surface air can be used to overcome poor boundary layer rendition and improve the quality of diagnosed stability indices. The model-derived approach allows relatively dense spatial distribution of possible proximity locations at high temporal frequency from which soundings can be taken. Numerical weather prediction (NWP) model-based pseudo-proximity soundings from a high-resolution NWP model such as MesoLAPS (Mesoscale Limited Area Prediction System) provide a three-hourly forecast dataset, and a uniform distribution of sounding locations in a $12.5 \mathrm{~km}$ grid over the entire continent. These advantages in proximity are balanced by the weakness in resolving the boundary layer and reduced vertical resolution in comparison to the radiosonde, which captures detailed profiles of actual environments. For the purposes of this study, MesoLAPS forecast data have been verified against radiosonde data and applied as pseudoproximity profiles to severe thunderstorm reports.

To compare the atmospheric profiles associated with severe thunderstorm reports, indicators are required to capture the important aspects associated with these environments. The development of thunderstorms relies on the presence of moist static instability in the atmosphere at a given location (Doswell 2001). The organization of thunderstorms, and the greater likelihood of severe weather is associated with vertical changes in the horizontal wind, commonly referred to as the vertical wind shear (VWS) (Weisman and Klemp 1982, Brooks et al. 1994). The link between VWS and instability means that an approach is required to characterise environments using more than one parameter in deriving covariates (Brown and Murphy 1996; Brooks and Dotzek 2006). The covariate approach has been particularly successful when indices identifying instability (e.g. Convective Available Potential Energy (CAPE) or Lifted Index (LI)) are combined with a quantity that describes VWS (Brooks et al. 2003). The selection of indices to analyze these aspects of convective development is a complex issue that can be influenced by available resolution, ease of calculation and reliability. This is discussed further in the proximity datasets and approach section. It follows that in order to capture an accurate profile of Australian severe thunderstorm environments, consideration of an appropriate set of indices is required, including covariate combinations. Using pseudo-proximity soundings, covariates are automatically calibrated to ensure their relevance in the Australian region.

The paper is organized as follows: The 'Severe thunderstorms database' section describes and discusses the severe thunderstorm database produced for this study. The 'Proximity datasets and approach' section reviews the strengths and weaknesses of the proximity datasets used to produce the environmental climatology and the approach taken by this study to identifying proximity environments. The 'Severe weather climatology' section describes the proximity climatology and environments found to be associated with severe thunderstorm reports and significant severe thunderstorm reports and relates them to operational forecasting quantities. In the 'Climatological discriminants' section, the discriminants determined between significant severe and severe thunderstorms are described and applied for the dataset and compared with studies in other parts of the world. Finally the 'Conclusion' section provides the conclusions, recommendations for the application of this research and discusses its future direction.

\section{Severe thunderstorm database}

\section{Development}

A database of 1550 severe thunderstorm events (Table 1) was produced from the Bureau of Meteorology (BoM) national severe thunderstorm records, significant weather summaries and other verifiable thunderstorm events for seven warm seasons (and part of an eighth) from March 2003 to April 2010. This period was chosen to match the availability of MesoLAPS data. The raw BoM dataset contained 3500 reports of severe phenomena from across Australia. Additional reports for Queensland and other reports not included in the database were collated from the significant weather summaries produced monthly by each State and raw report records. This set of reports was then screened for conformity to the Australian severe thunderstorm requirements (not including extreme rainfall); any one or more of hail in excess of $2 \mathrm{~cm}$, wind gusts in excess of $90 \mathrm{~km} \mathrm{~h}^{-1}$ or any tornadic event. This compilation of reports was then filtered over three stages to ensure that either there was recorded evidence of severe weather associated with thunderstorms, or damage was recorded with the only explanation being a thunderstorm. This first stage also involved the removal of reports not related to warm-season storms (particularly the case for cool-season tornadoes (Mills 2004; Kounkou et al. 2009) and wind

Table 1 Breakdown of details for the severe thunderstorm database (1550 reports overall, 242 reports of significant severe thunderstorms). Severe thunderstorm reports have severe weather equal or exceeding hail of $2 \mathrm{~cm}$, wind gusts of $90 \mathrm{~km} \mathrm{~h}^{-1}$ and tornadoes of any intensity, while significant severe events have hail in excess of $5 \mathrm{~cm}$, wind in excess of $120 \mathrm{~km} \mathrm{~h}^{-1}$ and tornadoes equally or exceeding F2 intensity. Reports are used to identify individual thunderstorms, with multiple occurrences of the same phenomena, or different phenomena being attributed to a single severe thunderstorm report with a maximum intensity for each phenomena recorded.

\begin{tabular}{lcc}
\hline Type of Event & Severe & Significant Severe \\
\hline Hail & 537 & 93 \\
Wind & 810 & 85 \\
Tornado & 48 & 14 \\
Wind and hail & 128 & 37 \\
Hail and tornado & 16 & 7 \\
Wind and tornado & 3 & 2 \\
Wind, hail and tornado & 8 & 4 \\
\hline
\end{tabular}


phenomena which occur in environments usually involving weak instability), reports which were questionable and/or inconsistent, and reports associated with tropical or nonthunderstorm low pressure events, all of which commonly occur in the database (Harper et al. 2001). Although there are likely some warm-season events that do occur within these low CAPE environments, we make this distinction to minimize the effects of poor environmental soundings in the sample.

The second stage of the filtering process involved stratification of reports into the severe or significant severe thunderstorm report categories and assignment of these reports to individual thunderstorms. For US events, significant severe weather is defined as $5 \mathrm{~cm}$ or greater hail, winds exceeding $120 \mathrm{~km} \mathrm{~h}^{-1}$ and tornadoes exceeding $\mathrm{F} 2$ intensity (Hales 1993; Doswell 2001), and any thunderstorm producing one or more of these phenomena was classified as such. However, the relatively small database, and lower mean values for Australian events meant that less than fifteen per cent of thunderstorm reports were classified as being significant severe. To identify reports associated with an individual thunderstorm, any report made within 40 $\mathrm{km}$ and two hours of another report was attributed to that thunderstorm event following the approach of Kelly et al. (1985). In the relatively rare case where a storm cell was particularly long-lived, these reports were still attributed in this way as long as the track of an individual thunderstorm could be identified.

The third stage involved dealing with missing data with regard to report magnitude, location of report and time of occurrence. Where the necessary facts were impossible to establish, reports were discarded. Where there was no reported hail size, damage indicators were used (particularly the case for hail exceeding $5 \mathrm{~cm}$ ) and information on hail size was interpreted from reference objects. When required, wind damage indicators were used with severe winds being identified using minor damage (such as falling branches and trees, minor house damage), and significant severe winds identified using major damage (roofs removed from homes, large numbers of trees uprooted, blown or thrown objects with no evidence of tornadic events). These were then assigned the minimum values for that threshold, 49 knots $\left(90 \mathrm{~km} \mathrm{~h}^{-1}\right)$ for severe, and $65 \mathrm{knots}\left(120 \mathrm{~km} \mathrm{~h}^{-1}\right)$ for significant severe. In the case of the tornado reports, damage ratings were given on the basis of the Fujita scale, provided sufficient evidence was available, otherwise they were assigned a minimum rating of F0. Unlike many tornado records, the Australian database contains additional information describing the nature of the tornado report. The intense tornado cases are much more likely to be reported given the associated damage. As we seek to examine the difference between severe and significant tornadoes, the weak cases can be rated F0 or F1 without having any negative implication for this study. Locations of reports in latitude and longitude were determined based on the information available and the nearest town information provided in the reports. If the time of occurrence or information of that nature was not included, a default afternoon value was assigned depending on the state of incidence to reflect the diurnal peak of the existing climatology (Fig. 1(d)). This corresponded to 0500 UTC in southeastern Australia, 0700 UTC in Queensland and the central States during daylight savings, and 1000 UTC in Western Australia. The choice of non-standard UTCs was to facilitate the analysis of the sounding derived prior to the report, and the sounding that was produced after the report with the maximum of the two selected.

\section{Description of database}

The severe thunderstorm reports are distributed across Australia, albeit sparsely, with the greatest concentrations close to the metropolitan centres and the heavily populated east coast, likely owing to observer density (Fig. 1(a)). This makes the inclusion of any warm-season thunderstorm that produces severe weather important to ensure that any derived discriminant is representative of the overall distribution of Australian severe thunderstorm environments, as opposed to being biased toward (or away from) any particular region. Reports from the tropical/subtropical regions that correspond to storms producing large hail have been included, as they are more likely to represent organized deep convective environments than the annual monsoonal convection. Of the 1550 reports, the majority result from damaging winds, and hail reports provide most of the remainder. Only 75 verifiable reports of warm-season tornadoes were observed over the period. A relatively consistent population of total reports is apparent, with six seasons having between 175 and 225 reports (Fig. 1(b)). There was a very large number of severe thunderstorms in 2005-2006 with nearly 300 reports, the reason for this apparent anomaly is not obvious from the database. Apart from 2005-2006 the number of significant severe weather reports also seemed to remain relatively consistent over the period despite the inter-annual variability of the total population.

Although previous studies have considered the cut-off for warm season thunderstorms in Australia to be between October and April, the database used here has a greater number of severe thunderstorm reports in September than in April (Fig. 1(c)). The average seasonal cycle of reports shows an increasing number between September and December, during the spring and early summer where environments with high CAPE and strong VWS are present, particularly over the southeast. The presence of both quantities in ample amounts in the period October to December also coincides with the greatest number of significant severe thunderstorm reports. As the summer pattern begins to dominate and dry air is present over the southeast and more monsoonal patterns dominate the north, the number of reports begins to decrease as organized storms become more rare. With decreasing diurnal forcing and the strengthening subtropical ridge reducing the frequency of favourable shear environments, the number of severe thunderstorm 
reports then decreases from February until the end of April. Based on the seasonal distribution of this climatology, the Australian severe convective warm season appears to lie between September and April, with few reports outside of this period. Reports outside of this period were more heavily scrutinized in order to justify their inclusion. This involved analyzing whether the environmental ingredients that preceded the storm were of those expected for warm-season thunderstorms.

Reports of severe thunderstorms peak in the late afternoon and evening, with less than five per cent of the sample occurring between midnight and midday, in adjusted local time. Within the remaining period, 80 per cent of the severe thunderstorm reports occurred between $3.00 \mathrm{pm}$ and $8.00 \mathrm{pm}$ local time (Fig. 1(d)). This is similar to previous results for Australian thunderstorms (Kuleshov et al. 2002) with a strong diurnal peak associated with the maximum surface heating. The agreement of this database of severe thunderstorms with those considered previously, together with the spatial distribution of environments that reflect a wide continental sample, suggest a database has been obtained that is appropriate for developing a proximity climatology of Australian severe thunderstorm environments.

Fig. 1 a) Spatial distribution of severe thunderstorm reports in Australia for the period March 2003 to April 2010. Black dots indicate individual severe thunderstorm reports (1550), red stars indicate Australian radiosonde stations (28), and blue letters show the stations used for verification (B - Brisbane, M - Moree, W (coast) - Williamtown and W (inland) - Wagga Wagga). b) Annual frequency of severe thunderstorm reports for the eight warm seasons (September-April) during the period. Black bars represent significant severe thunderstorms, while grey bars represent severe thunderstorms. The total peak represents the total number of reports of any classification. 2002-2003 was omitted as it was not a complete season.

c) Monthly frequency of severe thunderstorm reports with interannual variability. Horizontal lines correspond to the average number of severe thunderstorm reports per month for the period March 2003 to April 2010. The confidence intervals correspond to the maximum and minimum frequency of severe thunderstorm reports.

d) Hour of first reported phenomena associated with a severe thunderstorm for each of the 1550 reports, in local time. All times outside this period had a frequency of severe thunderstorm occurrence of a lower level than that shown for $12.00 \mathrm{pm}$.

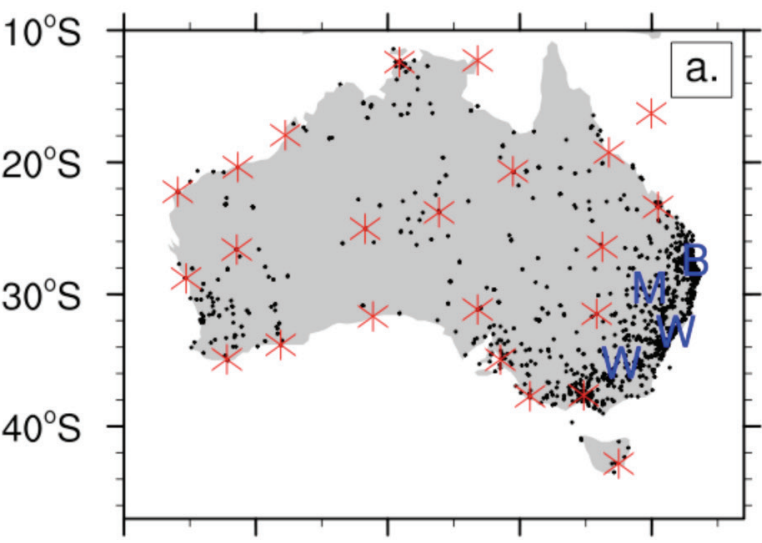

$110^{\circ} \mathrm{E} \quad 120^{\circ} \mathrm{E} \quad 130^{\circ} \mathrm{E} \quad 140^{\circ} \mathrm{E} \quad 150^{\circ} \mathrm{E}$

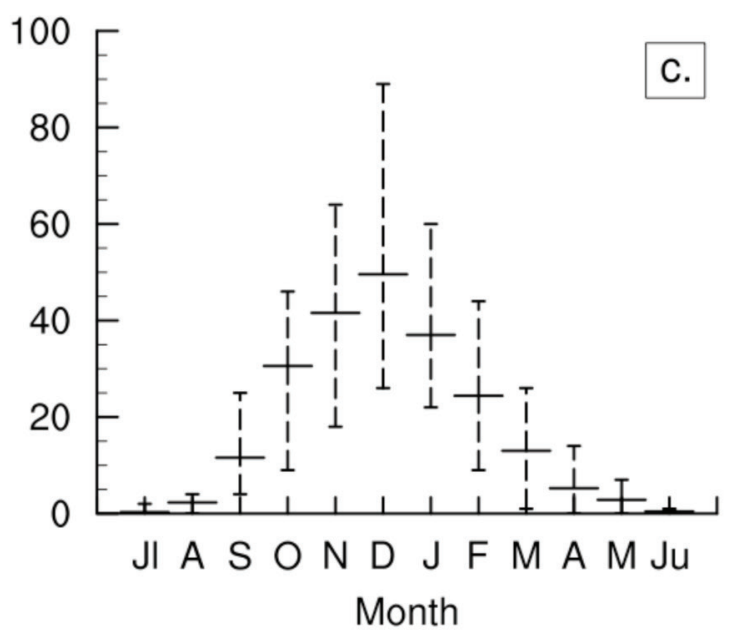

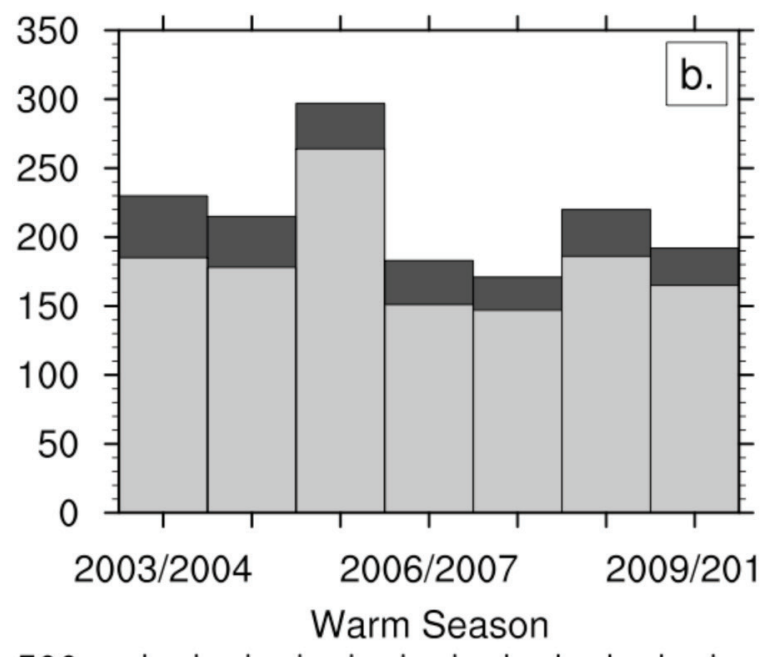

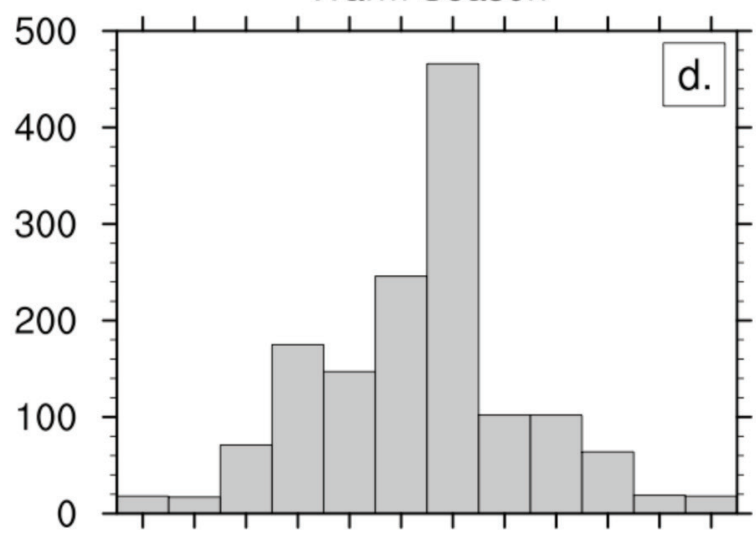

$12 \mathrm{pm} 2 \mathrm{pm} \mathrm{4pm} \mathrm{6pm} \mathrm{8pm} \mathrm{10pm}$ 


\section{Proximity datasets and approach}

\section{Sources of proximity data}

Two sources of data were used in this study to develop proximity soundings to describe severe thunderstorm environments: the sparse network in space and time of radiosonde profiles and the denser network and more frequent soundings from the MesoLAPS numerical weather prediction model forecasts.

Rawinsonde atmospheric profiles were used to verify MesoLAPS data and were derived for sixteen stations These were selected over a range of inland and coastal areas scattered across the continent to maximize the available number of comparisons and reliability of records. These stations were located south of $23^{\circ} \mathrm{S}$, which correspond to the northernmost extent of the majority of severe thunderstorm reports. This allowed comparison of stations from the subtropics to the mid-latitudes where the greatest frequency of severe convection is located, thereby allowing the sampling of a large range of environments. Four stations were identified to examine specific environments, two coastal (Brisbane, Williamtown), and two inland locations (Moree, Wagga Wagga (hereafter Wagga)), in each case from the subtropics and mid-latitudes respectively (Fig. 1(a)). Soundings were removed during the quality control process to address missing levels and missing data from the radiosonde data. Owing to station recording frequency and limitations surrounding the launch of balloons in the event of failure, only 0000 UTC soundings were retained. These data were then interpolated onto a MesoLAPS vertical grid for the calculation process.

MesoLAPS was the mesoscale NWP system used operationally from January 2002 until July 2010 in the BoM, and was nested within the larger model domain Limited Area Prediction System (LAPS) model (Puri et al. 1998). The initial conditions for MesoLAPS were based on an interpolation from the $37.5 \mathrm{~km}$ LAPS to a model grid domain of $12.5 \mathrm{~km}$, while also interpolating from 61 to 29 levels. MesoLAPS was then run to produce three-hourly forecasts over 36-hour periods of variables including temperature, water vapour mixing ratio and winds, which were used to produce the pseudo-proximity soundings. Variables were then derived from the MesoLAPS profiles over the period March 2003 to April 2010. The comparison set was broken down into two categories, one considering a direct nearest point profile comparison, and the other considering the maximum CAPE of all grid-points within a 7-by-7 grid centred at the rawinsonde location. This produced a maximum spatial distance of $53 \mathrm{~km}$ between the sounding chosen and the rawinsonde, with the majority of potential points closer than this. The latter was applied to examine the influence of proximity choices within the model environment and minimize model sensitivity to profile differences over relatively small scales.

\section{Convective parameters}

As was briefly discussed in the introduction, the selection of indices for analyzing ingredients present in the atmosphere in severe thunderstorm environments presents difficulties. While the key ingredients of organized deep convective processes can be taken to be a combination of instability and shear, representations of this can be problematic. Instability can be examined by considering either a simple fixed layer index or a more complex index such as CAPE, which considers buoyancy over the depth of the atmosphere. A lifted index to $500 \mathrm{hPa}$ (LI) was used for this dataset to help compare the proximity soundings of observed reports to forecasting thresholds used by the BoM. Although such variables are simple to calculate compared to the integration of CAPE, the selection of a single atmospheric layer for the purpose means that instability can be missed or neglected by not choosing the most-unstable layer. This integration over depth means that CAPE often provides a better overall profile of instability than fixed-layer measures of instability (Blanchard 1998). However, little meaningful distinction has been identified in CAPE values between storms that produce hailstones and those that do not (Knight and Knight 2001). In contrast, the relation of CAPE to potential updraft velocity has been proposed to be useful in distinguishing between non-severe and severe hail (Ryan 1992; Niall and Walsh 2005). There are also limitations to the method of calculation of CAPE and it is particularly sensitive to fluctuations in the surface moisture and boundary layer environment, or in environments that require forcing (Ryan 1992; Doswell and Rasmussen 1994; Riemann-Campe et al. 2009). To overcome these issues, in this study CAPE was calculated using a most unstable CAPE (MUCAPE—-based on potential temperature) with the lowest level provided by a mixed-layer. For this purpose a 50-mb deep mixed-layer CAPE (MLCAPE) was calculated, and then the maximum CAPE from the profile chosen. This assisted in moderating the issues surrounding elevated convective environments and weaknesses in resolving of boundary-layer environments. Given that CAPE provides a better overall estimate of the atmospheric instability present in most cases, this was applied for the discriminant analysis rather than a fixed layer index.

Another important quantity related to moist static stability is Convective Inhibition (CIN). CIN measures an environment's capping of convection via the presence of an atmospheric layer warmer than that of a convective parcel (Tailleux and Grandpeix 2001). Resistance to convection allows a larger amount of instability to build up before explosive release, and therefore has important implications for thunderstorm initiation and timing the release of instability. However, due to resolution and parameterization, CIN is considered an unreliable quantity from reanalysis or model-derived proximity soundings. As it also does not directly assess the potency of a severe thunderstorm environment we only briefly discuss CIN within the 'Severe weather climatology' section of this study.

In the presence of instability, a second and no-less important ingredient for severe thunderstorms is VWS, which can influence storm longevity and promote organized 
storm structure allowing the production of severe weather for longer periods. The magnitude of the VWS (Weisman and Klemp 1982) and its directional change with height (Brooks et al. 1994) have been shown to be important for determining convective mode. This interaction relies on maintenance of the cold pool associated with convective downdrafts, separation between the updraft and downdraft interface achieved by increasing wind speed with height (thereby carrying precipitation downstream), and provided sufficient magnitude and appropriate directional change inducing rotation within the thunderstorm updraft. While each of these processes is critical for determining the convective mode of a storm, the potential for severe weather has been found to have a greater dependence on the magnitude of VWS rather than directional change (Doswell 2001). Deep-layer VWS (S06), the magnitude of the wind shear between the surface and $6 \mathrm{~km}$ is an effective quantity in distinguishing storm organizational mode (Weisman and Klemp 1982). Strong VWS is essential for the development of significant hail events and tornado environments, but is not as important for severe wind events (Dean and Schneider 2008). As this study approaches the problem using modelderived proximity soundings, the direction of the shear vectors may be less reliable particularly in the near-surface layers. In view of this, only magnitude has been considered, which also simplifies calculation. Bulk VWS was calculated between the surface and two reference levels; one and six kilometers above the surface.

\section{Verification of Mesolaps Forecast Data using Radiosonde}

To establish the viability of the high-resolution MesoLAPS forecast proximity data for application as pseudo-proximity soundings, comparison was made with all radiosonde soundings at 0000 UTC for which the CAPE exceeded $10 \mathrm{~J}$ $\mathrm{kg}^{-1}$ (4983 soundings). Direct comparison of the nearest gridpoint sounding suggests that 0-6 km VWS from MesoLAPS produces comparable values to those determined from radiosonde data (Fig. 2(c)). CAPE was found to be poorly reproduced, with a very large scatter (Fig. 2(a)). However, the correlations associated with these comparisons are clearly positive, particularly when the individual inland stations are considered (Fig. 3). However, in the cases of moderate to high radiosonde CAPE, the overall performance of the MesoLAPS data improves (exhibited by the relatively small number of compared environments in the low MesoLAPS, high radiosonde region). The performance in low CAPE radiosonde environments is not unexpected (particularly for the forecasts prior to July 2007 which are twelve-hour forecasts from 1200 UTC), as issues with the vertical resolution and rendering of local effects become more important when dealing with relatively marginal CAPE environments. The environments that exhibit low MesoLAPS CAPE compared to high radiosonde CAPE are likely examples of where the model may not perfectly match the observed environment. This may be caused by sub-gridscale processes or localized effects that contribute to the environment, the vertical resolution of the model, or the positioning of the environmental pattern by the model being out of sync with the observed environment. This can be partially counteracted by searching a number of MesoLAPS points for maximum CAPE. To achieve this, the maximum CAPE from a 7-by-7 proximity 'area' centred at the sounding location was applied (Fig. 2(b)). While there is still some misrepresentation at low radiosonde CAPE (when high MesoLAPS CAPE is produced), we seek primarily to sample environments that have conditions conducive to severe convection, which generally occur with CAPE above $500 \mathrm{~J} \mathrm{~kg}^{-1}$. We note that some over-estimation is possible due to use of this maximum CAPE approach, but assert that it does increase the number of environments that are resolved by the model. It is recognized that this scatter from data is less than optimal for the application. However, in order to produce a gridded field we believe this produces a reasonable outcome.

Although MesoLAPS forecast CAPE does have significant scatter, limitations in the radiosonde network, particularly with the respect to the timing of flights, mean that the benefits of model-derived proximity soundings likely outweigh the limitations. There are also significant differences between the four radiosonde sites, with CAPE in the coastal locations often poorly represented (Fig. 3(a),(d)). In inland cases, there is generally overestimation of CAPE values by the forecast data but an overall better agreement than the coastal locations, likely due to localized transport effects playing a more limited role inland. This is particularly pronounced in Brisbane, where the airport sounding is very close to Moreton Bay and likely affected by sea breeze patterns, whereas Williamtown RAAF soundings are more shielded by topography and influenced from surface flow down the Hunter Valley. Given the limitations stated above, the maximum CAPE within a 7-by-7 grid radius was applied for the climatology in order to produce the closest environmental profile possible. This allows not only the sampling of effectively unmixed environments, but also to sample the environment more likely to be realized by the thunderstorm that produces a severe thunderstorm report. However, it is acknowledged that the gridded dataset does not always necessarily produce a representative value.

In contrast to the limitations of CAPE, S06 is relatively well represented in the MesoLAPS forecasts, with a distribution closer to one-to-one (Fig. 2(c),(d)). The variations between rawinsonde and MesoLAPS profiles for this quantity likely arise from poor forecasts of near-surface winds within the 0-1 km layer (not shown). This differs from the findings of Thompson et al. (2003) for a $40 \mathrm{~km}$ resolution mesoscale model that found little discernable difference in shear values. Smaller differences were found to exist between bulk shear in the 1-6 km layer, particularly in the mid-latitudes. The representative aspects of this shear are poorer for the coastal cases (Brisbane, and to a considerably lesser extent Williamtown which is at the end of a valley that allows infiltration of inland air), where localized sea-breezes and 
Fig. 2 a) Nearest point to station comparison of MUCAPE calculated from radiosonde profile and MesoLAPS forecast profile (4968 soundings from stations south of Rockhampton for the period March 2003 to April 2010, soundings from MesoLAPS correspond to 1200 UTC 12-hour forecasts for the period March 2003 to July 2007, and from August 2007 to April 20101800 UTC six-hour forecasts). A 1 to 1 ratio dashed line is shown.

b) As for a) except MesoLAPS profile is from the most unstable (CAPE) profile within a 7-by-7 grid-point box centred on the nearest point to station.

c) As for a) except 0-6 km vertical wind shear.

d) As for b), except 0-6 km vertical wind shear.
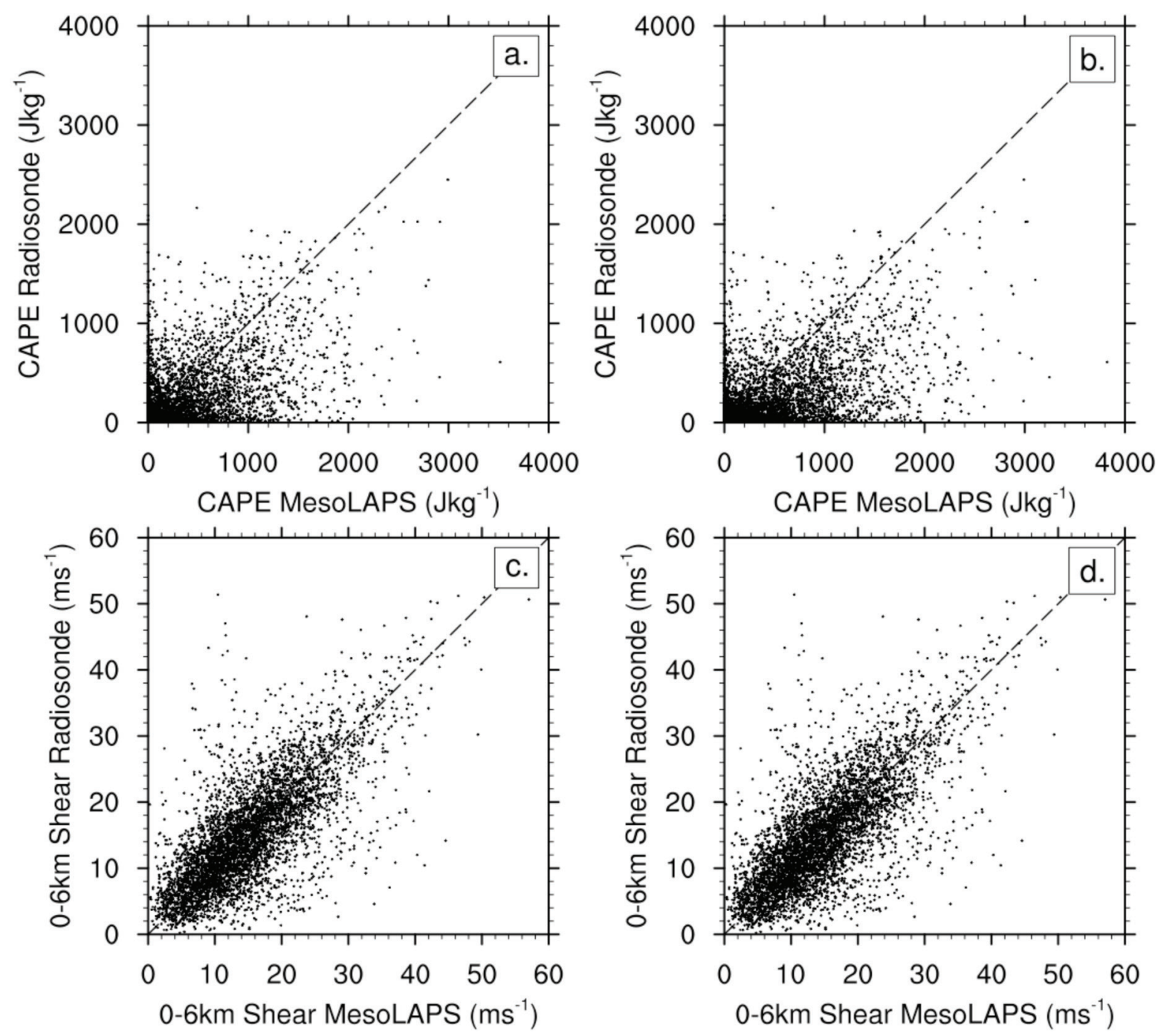

environment intrusion may present difficulties for the model. This is contrasted by the excellent agreement at inland locations of Moree and Wagga where deep layer VWS is more representative (Fig. 4). We therefore note that care must be taken in interpreting bulk shear environments in coastal areas, and indeed any covariate discriminant derived from such values.

\section{Proximity conditions}

The frequency of MesoLAPS forecasts provides a threehourly source of pseudo-proximity soundings, with any report being within two hours of a pseudo-sounding. This provides a distinct advantage when compared to the proximity offered using 0000 UTC radiosonde soundings that occur six hours from the peak convective period. To

deal with mis-sampling and soundings that may have been convectively contaminated, pseudo-soundings were chosen based on being within an hour of the report prior to or after the reported event occurred. In the case when the chosen sounding had CAPE less than $10 \mathrm{~J} \mathrm{~kg}^{-1}$, the next closest sounding was also considered. Both the pre- and postevent soundings were calculated, and the sounding with the maximum CAPE of the two chosen. Spatially, reports were approximated to the nearest MesoLAPS grid point (on the $12.5 \mathrm{~km}$ grid), and soundings calculated for that grid point, and all other gridpoints within a 7-by-7 grid-point box centred on the report. Convective variables were calculated using these conditions for all proximity soundings and assigned to their respective severe weather reports. 
Fig. 3 Comparison of CAPE calculated for radiosonde profiles to that determined from the most unstable MesoLAPS forecast sounding within a 7-by-7 grid-point box centred on the point nearest the radiosonde stations indicated in Fig. 1(a) over the period March 2003 to April 2010 for a) Brisbane (720 soundings), b) Moree (413 soundings), c) Wagga Wagga (322 soundings), and d) Williamtown (681 soundings). Note that these comparisons only consider cases of CAPE >10 J kg-1. A 1 to 1 ratio dashed line is shown.
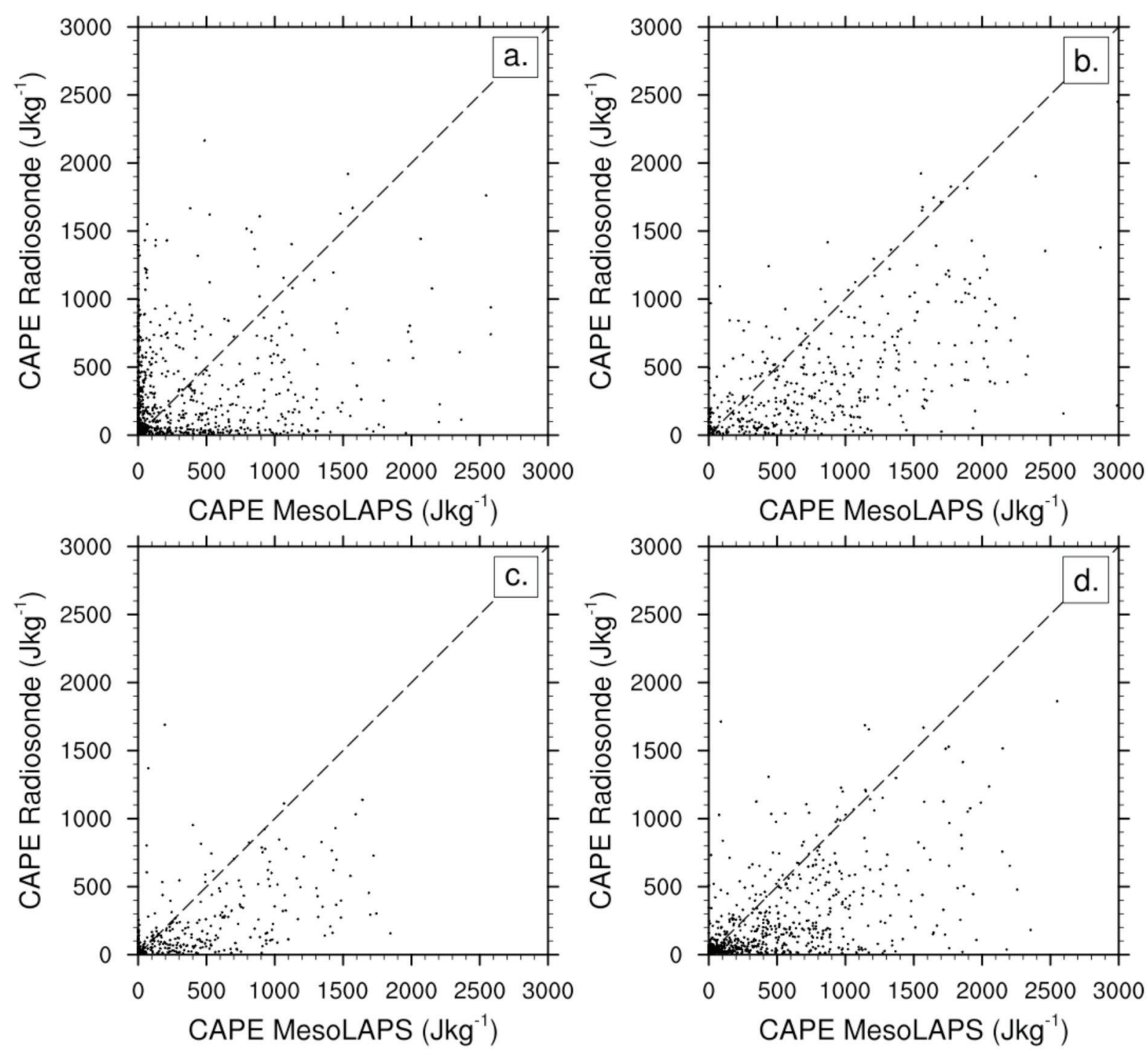

\section{Severe weather climatology}

Proximity soundings were constructed for the entire database. Of these soundings, 116 cases of CAPE less than $100 \mathrm{~J} \mathrm{~kg}^{-1}$ were examined and found unlikely to be representative and thus excluded from this analysis. This approach is similar to that used by Rassmussen and Blanchard (1998) and Brooks et al. (2003) and assumes that values less than this are more likely to be associated with a poor proximity sounding or problems within the model in determining an appropriate profile. The distribution of CAPE, 0-6 km shear and LI500hPa were considered for each severe weather report, after classification of the report into significant severe (226 soundings) and severe (1208

soundings) categories. CIN ( $\mathrm{J} \mathrm{kg}^{-1}$ ) was also considered but the sample did not yield a useful distinction between severe and significant severe. The average CIN of both samples was less than $25 \mathrm{~J} \mathrm{~kg}^{-1}$ with only five per cent of both categories exceeding this threshold. However the average CIN is slightly higher for the significant severe category. This lack of distinction is not surprising given the environment that is identified is chosen to be the most unstable and favourable to severe thunderstorms. If CIN were to be considered, soundings prior to the occurrence of the convection would need to be explored, most likely between 0000 UTC and 0600 UTC to ascertain the nature of the inhibition in the environment prior to the development of unstable parcels. Therefore, for the remainder of this climatology, only CAPE 
Fig. 4 As for Fig. 3, except comparison of 0-6 km Vertical Wind Shear for the respective stations and soundings with CAPE $>10 \mathrm{~J}$ $\mathrm{kg}^{-1}$. A 1 to 1 ratio line is shown.
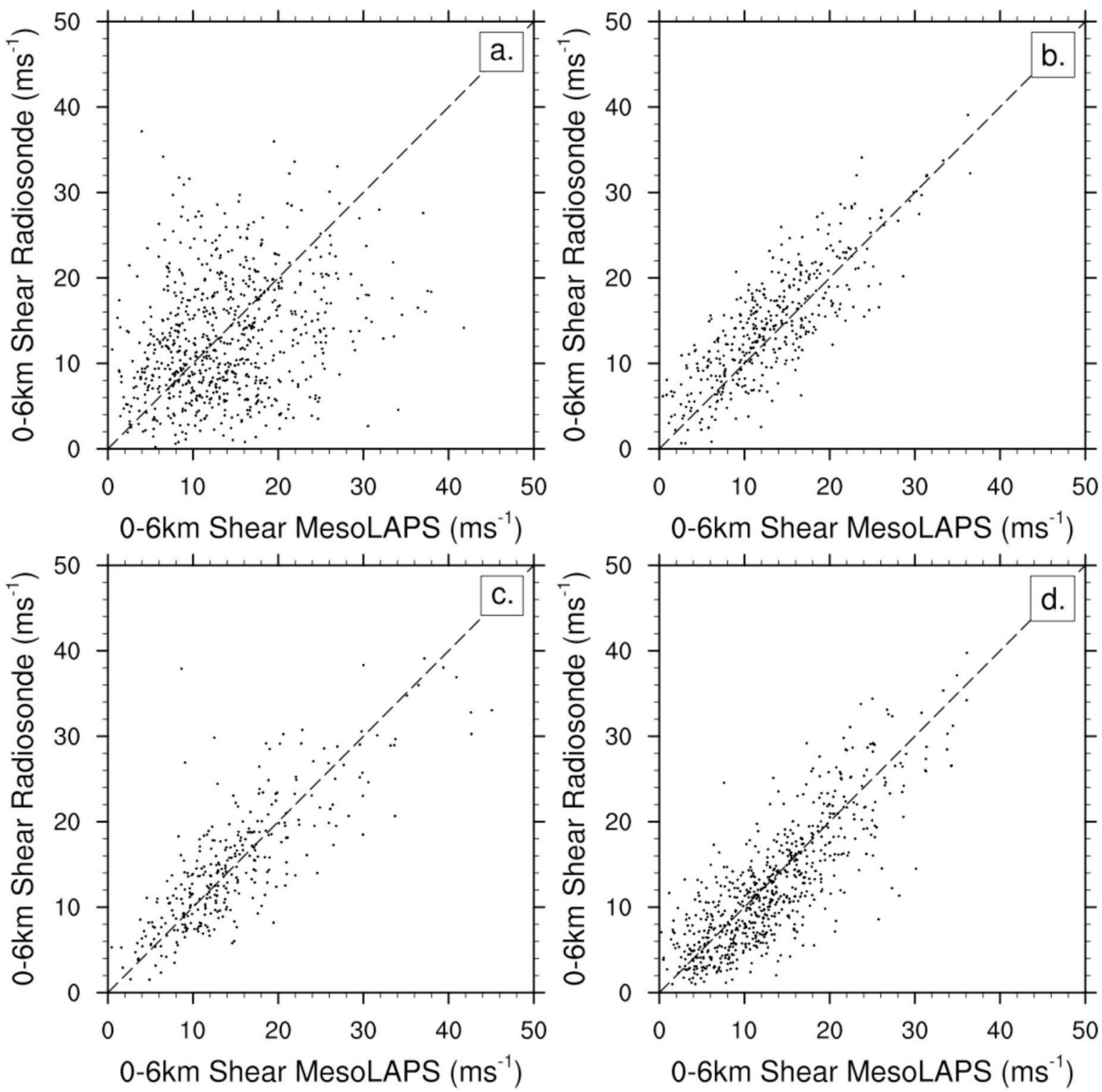

and S06 will be considered for purposes of discriminating severe thunderstorm environments, and LI500hPa for a forecast comparison.

The distribution of severe thunderstorm CAPE is characterized by the frequency of environments declining with increased instability (Fig. 5(a)). The largest proportion of environments is found with CAPE less than $2400 \mathrm{~J}$ $\mathrm{kg}^{-1}$, decreasing from $100 \mathrm{~J} \mathrm{~kg}^{-1}$ to the outer limits of the population. In contrast, the distribution of significant severe CAPE environments is centered around a CAPE peak between 1600 and $2000 \mathrm{~J} \mathrm{~kg}^{-1}$, again with a decrease thereafter. This suggests that significant severe events are more likely to occur with increased CAPE. However, extreme CAPE above $2500 \mathrm{~J} \mathrm{~kg}^{-1}$ is rare. The distribution of CAPE for severe environments may display the decay owing to the likely skewing of the population towards lower

CAPE by environmental samples that do not reflect the environment preceding the reported severe thunderstorm events. In comparison to proximity soundings derived from reanalysis data in the US (Lee 2002) where 60 per cent of the population is less than $2000 \mathrm{~J} \mathrm{~kg}^{-1}, 75$ per cent of Australian significant severe thunderstorms fall below this value. For the lower CAPE values of the distribution, 35 per cent of US significant events fall below $1200 \mathrm{~J} \mathrm{~kg}^{-1}$ as compared to 38 per cent for Australian cases. Considering the 90th percentile, Australian significant severe storms generally peak at $2600 \mathrm{~J} \mathrm{~kg}^{-1}$, compared to $3300 \mathrm{~J} \mathrm{~kg}^{-1}$ in the US. This suggests that Australian significant severe thunderstorms occur in environments with appreciably lower CAPE than those storms in the US, particularly in very high CAPE cases. A caveat to this is that the method may have produced CAPE values that are biased low, although the positive correlations 
Fig. 5 Distribution of proximity soundings for the Australian severe thunderstorm database, with all cases of CAPE $<100 \mathrm{~J} \mathrm{~kg}^{-1}$ removed as non-representative, for a) MUCAPE, b) 0-6 km vertical wind shear, and c) Lifted Index to $500 \mathrm{hPa}$. There are 1208 severe thunderstorm proximity soundings, represented by grey bars without borders, and 226 significant severe thunderstorm proximity soundings represented by grey bars with black borders. Totals peak is non-cumulative.
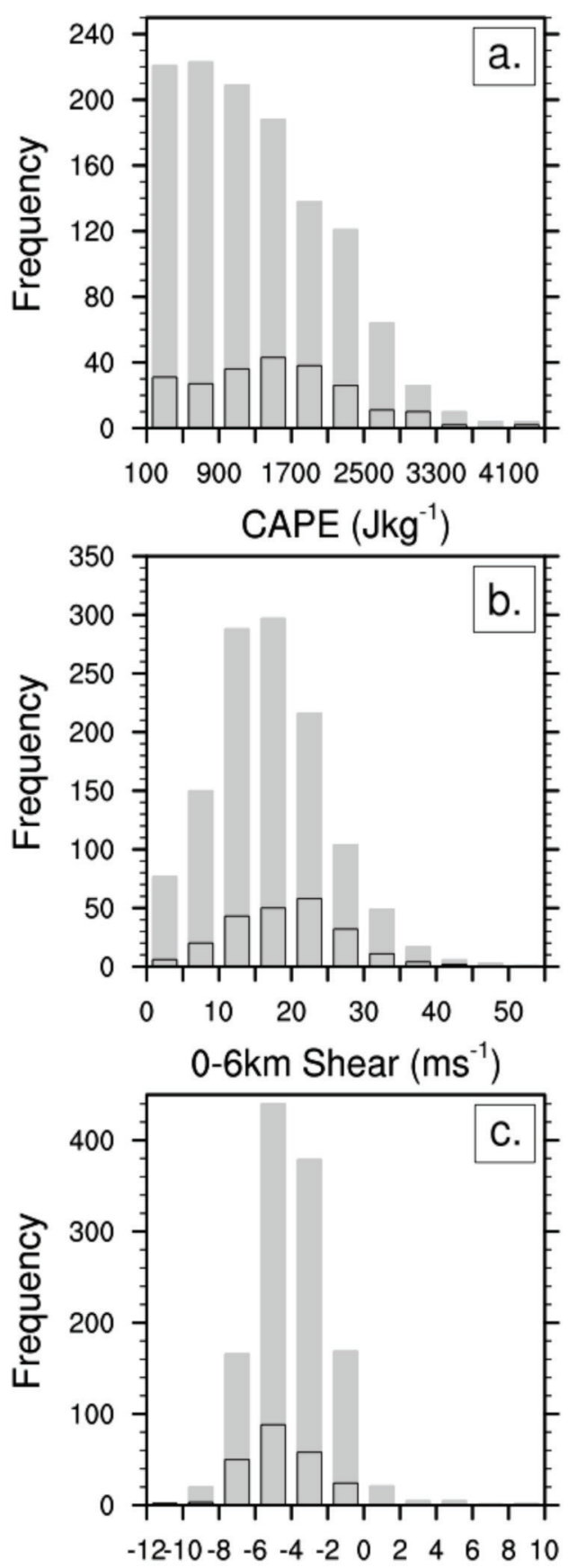

Lifted Index to $500 \mathrm{hPa}\left({ }^{\circ} \mathrm{C}\right)$ in Fig. 3 would seem to contradict this. The CAPE difference for the US proximity climatology is also probably greater than that shown here, as MesoLAPS offers a much higher vertical and horizontal resolution than the NCEP reanalysis upon which the US study was based.

Vertical wind shear is characterized by a more obvious difference between severe and significant severe thunderstorms, similar to the distinction present in the CAPE distribution. Significant severe thunderstorms in Australia occur in stronger S06 environments than those that produce severe thunderstorms. Both populations display distribution characteristics close to normal, with a central point at $15 \mathrm{~m} \mathrm{~s}^{-1}$ for severe thunderstorms, and 20-25 $\mathrm{m} \mathrm{s}^{-1}$ for significant severe thunderstorms (Fig. (5b)). This suggests that organized thunderstorms produce the majority of both severe and significant severe thunderstorms. In contrast to the lower CAPE figures shown between significant severe thunderstorms in Australia compared to the US, S06 has a very similar distribution. Where 50 per cent of the US proximity soundings fall below $20.5 \mathrm{~m} \mathrm{~s}^{-1}, 52$ per cent of Australian storms fall below the same threshold, and a similar case holds for both the 75th percentile and 90th percentile (falling within $1 \mathrm{~m} \mathrm{~s}^{-1}$ ). As would be expected, the balance between shear and CAPE plays an important role and likely contributes to the distribution and overlap for both quantities. However, it is clear from the climatology of these quantities that the role of S06 has a slightly greater importance in the Australian severe thunderstorm environments climatology, and this should be reflected in any discriminants determined.

The BoM forecast thresholds (Deslandes et al. 2008) do not aim to forecast for severe or significant severe weather as a whole, but there are guidelines for large hail and organized thunderstorms that rely on a consideration of both instability and shear. The supercell thunderstorm thresholds for shear in Australian conditions suggest that deep layer shear over $15 \mathrm{~m} \mathrm{~s}^{-1}$ is favourable for supercells, and greater than $18 \mathrm{~m} \mathrm{~s}^{-1}$ is very favourable (Deslandes et al. 2008). This suggests that the distribution of conditions observed for both the severe and significant severe thunderstorm cases would likely meet those favourable for supercell thunderstorms, with supercells much more likely to be the cause of significant severe phenomena. However based on this threshold, it is difficult to establish whether this mode of storm is likely to have caused all these reported events, as this relies more on the nature of the shear profile (distribution of the bulk shear vector and the curvature), which is difficult to ascertain. LI500hPa (the lifted index of a surface mixed-layer parcel lifted adiabatically to $500 \mathrm{hPa}$ ) is also a commonly used index by forecasters in Australia (rather than CAPE), with -4 or below again considered to be favourable to supercells. The distribution of LIs for the severe thunderstorm reports also peaks between -4 and -6 , with significant severe centered fairly close to this (Fig. 5(c)). Given that CAPE environments of less than $100 \mathrm{~J} \mathrm{~kg}^{-1}$ are discarded from the distribution, a number of poorly sampled LI environments still remain, 
and this may reflect the limitations of using a single layer parameter as a forecast quantity. However, CAPE appears to provide a more appropriate discriminant between significant severe and severe, with a more marked distinction between the two categories.

Despite the partial separation of both the CAPE and S06 significant severe and severe populations, no one variable provides an adequate discriminant between Australian significant severe thunderstorm and severe thunderstorm environments. There is also a noticeable difference in the CAPE climatology between Australia and the US, which suggests a greater dependence on S06 to produce significant severe thunderstorm environments in Australia. Therefore a covariate approach has been taken which considers instability over many layers in the atmosphere (CAPE) and shear within the deep layer (S06).

\section{Climatological discriminants}

An Australian significant severe thunderstorm discriminant We now seek an appropriate combination of CAPE and wind shear that can discriminate between environments conducive to the formation of severe and significant severe thunderstorms, or indicate the higher probability of occurrence for a significant severe thunderstorm.

The discriminant (Eqn 1) for significant severe thunderstorms determined by Brooks et al. (2003) was applied to the MesoLAPS proximity sounding climatology (Fig. 6(a)).

$1.79 \log _{10}(C A P E)+2.86 \log _{10}(S 06) \geq 8.36$

which simplifies to:

$$
\text { CAPE x } S 06^{1.6} \geq 46800
$$

A second discriminant has commonly been used as an approximation to Eq. 2 (e.g. Marsh et al. 2009), the line of constant CAPE-S06 product defined by:

$$
C A P E \times S 06 \geq 10000 \mathrm{~m}^{3} \mathrm{~s}^{-3}
$$

However, where Eq. 3 is used as a discriminant for significant severe environments, it was found that the Probability of Detection (POD) and the False Alarm Ratio (FAR) were far from desirable in the sample for the Australian case (Table 2). This is contrary to the Critical Success Index (CSI) (Donaldson et al. 1975), which would suggest that by lifting the threshold there is an improvement in the successful performance. CSI measures the ratio of successful forecasts (in this case significant severe being predicted by the discriminant) to the total number of successful forecasts, observed but not forecast (predicted severe rather than significant severe) and failed forecasts (severe but forecast significant severe). However, given the relatively small sample size that continues to decrease as the threshold is
Fig. 6 a) Distribution of proximity soundings for severe thunderstorm reports (dots) and significant severe thunderstorm reports (red stars) in log(CAPE)$\log (\mathrm{S} 06)$ phase space. Two lines for discriminants are shown, (from top left) the original Brooks et al. (2003) defined by Eq. 2 (line 1) and the approximation constant product (Eq. 3) (line 2).

b) As for a), except discriminant lines determined using linear discriminant analysis for subsets of Australian significant severe thunderstorms and severe thunderstorms. The centre line corresponds to the discriminant determined for the entire dataset (Eq. 4) (line annotated 4) with the maximum and minimum discriminant lines $(+,-$ respectively) determined with single years removed of CAPE $\times 506^{2.017} \geq 288204$ and CAPE x S06 $6^{1.339} \geq 47097$.
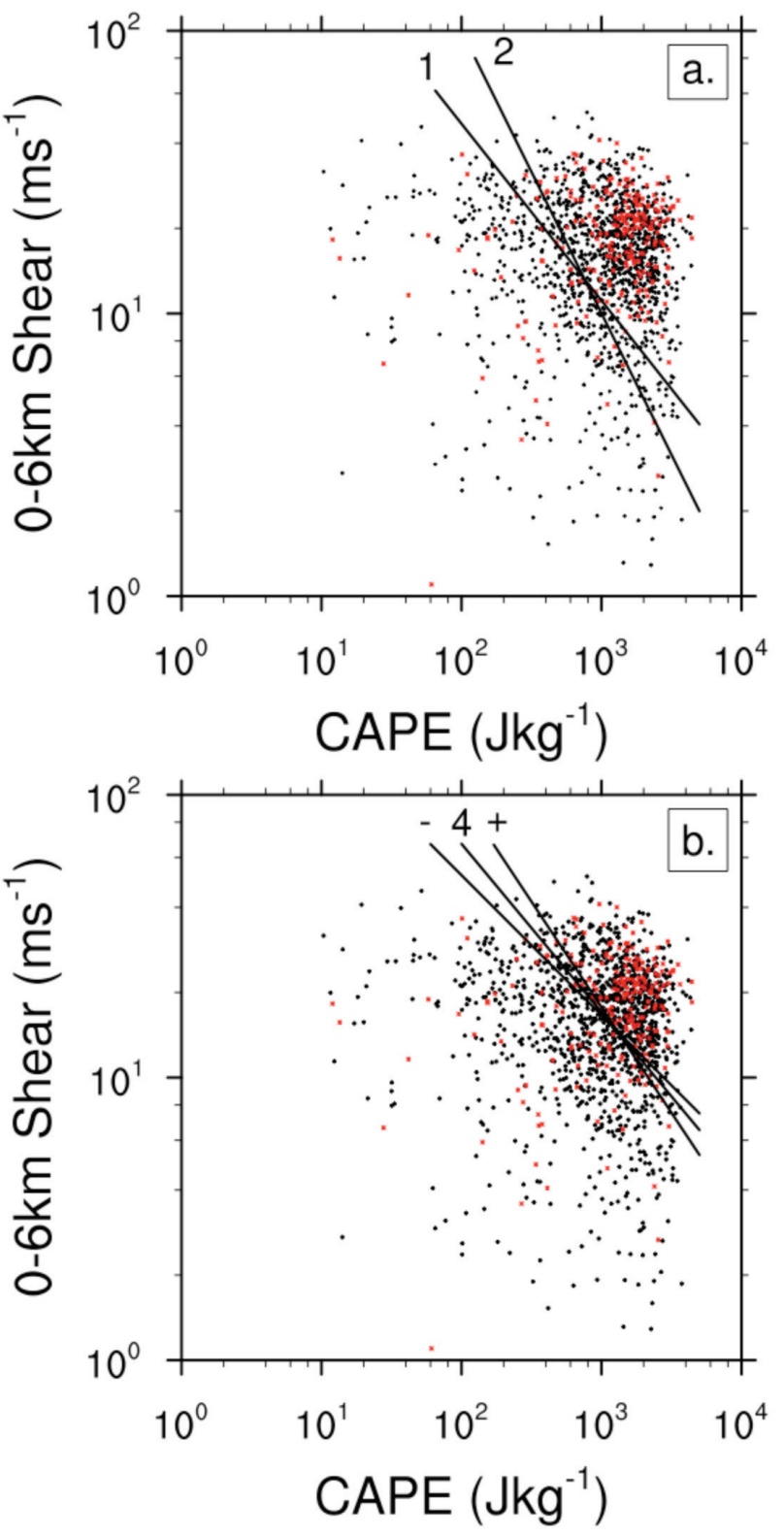
lifted, this produces the statistical aberrations commonly associated with the CSI (Schaefer 1990). In this case a small number of successful outcomes in an otherwise large total number of events produces this bias. Permutations of the US constant CAPE-S06 discriminant were examined for their suitability against the sample as approximations, but none were found to be suitable or a significant improvement. The difference between the performance of the constant product and the discriminant determined from the US significant severe climatology by Brooks et al. (2003) seems to be an unintentional compromise in performance (Table 3 ) in terms of POD and FAR. Returning to the Brooks discriminant (Eq. 2), initially the setting appears to be low visually, with a relatively high POD value, but a high FAR as well. We note that this difference may result as the analysis here was determined for proximity environments given by the much higher spatial and temporal resolution forecast data from MesoLAPS compared to the NCEP reanalysis used by Brooks. There is also the possibility that the increased CAPE generated by the proximity criteria and MesoLAPS in general may have skewed the distribution somewhat. As the Brooks discriminator did not appear to be a good fit, a discriminant was sought for Australian significant severe thunderstorm environments.

A formal linear discriminant analysis was performed (Fisher's Linear Discriminant for two groups (Wilks 2006)) using the limited significant severe sample available from the climatology. The relatively small sample available for consideration meant that care had to be taken to ensure the years which composed the sample did not adversely affect the discriminant determined, and therefore a set of discriminants was examined: the actual linear discriminant (hereafter the central) and a slope of minimum and maximum angle from the set of discriminants determined with individual warm seasons removed. The discriminant method relying on the centroid of the set of points meant that the three lines pass through a common point (Fig. 6(b)). The central discriminant achieves a POD to FAR separation of 0.2, which improves

Table 2 Probability of Detection (POD), False Alarm Ratio (FAR) and Critical Success Index (CSI) for values of constant CAPE-Shear product. Product of 10000 corresponds to the approximation to the original discriminant determined by Brooks et al. (2003), units of all products are $\mathrm{m}^{3} \mathrm{~s}^{-3}$.

\begin{tabular}{lccc}
\hline CAPE-Shear Product & POD & FAR & CSI \\
\hline 5000 & 0.916 & 0.872 & 0.127 \\
6000 & 0.898 & 0.830 & 0.167 \\
7000 & 0.881 & 0.797 & 0.197 \\
8000 & 0.858 & 0.767 & 0.224 \\
9000 & 0.836 & 0.738 & 0.249 \\
10000 & 0.819 & 0.704 & 0.277 \\
11000 & 0.796 & 0.671 & 0.303 \\
12000 & 0.779 & 0.647 & 0.321 \\
\hline
\end{tabular}

on the small difference achieved using any of the constant CAPE-Shear product lines, and slightly on that of the Brooks et al. discriminant. The angle of this discriminant line was kept the same, and shifted in the log(CAPE)-log(S06) space through the sample to assess the distribution of POD and FAR achievable (Table 3). Very similar separation was present through the sampled values and therefore there is little to be gained by increasing or decreasing the discriminant from this value. CSI also produces an optimum result close to the determined discriminant, however, given the difference is small and decreases the sample size still further, the linear discriminant appears the optimum combination of detection and false alarm that is possible. The central discriminant for Australian significant severe thunderstorm events is defined by the function:

$$
0.721 \log _{10}(C A P E)+1.21 \log _{10}(S 06) \geq 3.66
$$

which simplifies to:

$$
\text { CAPE } \times S 06^{1.67} \geq 115000
$$

Comparison was made to the US criteria of this newly determined discriminant, and the difference was found to result from the angle, with shear playing a slightly greater role in Australian significant severe thunderstorm environments. Whether this distinction reflects an actual environmental difference, however, requires a comparison using a dataset with similar horizontal resolution, rather than the high-resolution NWP forecasts used here. Based on this, it is suggested that any further lifting of the threshold might be too restrictive to identify even the limited number of significant severe events that occur in Australia. At the lower

Table 3. POD, FAR and CSI for discriminant lines determined using the Australian proximity database, with variations in the value of constant chosen while slope is maintained constant. The centre line corresponds the formal linear discriminant (Eq. 4), with the effect of the maximum and minimum variations in the discriminant POD and FAR shown. The POD/FAR for the Brooks et al. (2003) discriminant is shown next to the PSS constant given the similarity of POD/FAR ratios.

\begin{tabular}{lccc}
\hline Discriminant Constant & POD & FAR & CSI \\
\hline 3.45 & 0.823 & 0.687 & 0.293 \\
3.50 & 0.801 & 0.662 & 0.312 \\
3.55 & 0.770 & 0.618 & 0.343 \\
3.60 & 0.730 & 0.576 & 0.366 \\
3.65 & 0.695 & 0.519 & 0.397 \\
3.66 (Centre) & $0.686 \pm 0.018$ & $0.501 \pm-0.014$ & 0.406 \\
3.70 & 0.646 & 0.454 & 0.420 \\
3.75 & 0.566 & 0.397 & 0.412 \\
3.80 & 0.500 & 0.329 & 0.401 \\
3.85 & 0.460 & 0.266 & 0.394 \\
3.90 & 0.394 & 0.202 & 0.358 \\
\hline
\end{tabular}


end of this discriminant, we suggest there is a 'grey area' that is composed of a mixture of almost significant severe events (e.g. golfball sized hail at 4 to $4.5 \mathrm{~cm}$ ), and CAPE-Shear environments which produce significant severe conditions but do not exist in an environment above the somewhat arbitrary threshold. This grey area was determined by first taking the discriminant line determined for the Australian environment and shifting it in CAPE-Shear phase space until the area bounded by the line between the maximum shear/minimum CAPE point and the minimum shear/ maximum CAPE point was equal (Fig. 7). Reports that fall into this category can be referred to as Potentially Significant Severe (PSS), being reports which are certainly severe, but potentially more so. This forms the second discriminant line for Australian severe thunderstorm environments and acts as a safeguard for problems caused by the small sample size and is identified by:

CAPE x $S 06^{1.67} \geq 68000$

This boundary to the grey area was found to be of a very similar location and slope as the Brooks et al. discriminant described above, with the POD and FAR being within 0.001. Accordingly the Brooks et al. discriminant could easily be substituted to act as this grey area for comparison purposes to other regions in climatological studies of convective environments.

Determining a discriminant for severe thunderstorm environments.

Extending the application of the significant severe discriminant, a limit was examined for severe thunderstorm environments. While a FAR was not possible due to the lack of a null sample, by using POD the proportion of severe events was used as a proxy (Table 4). A discriminant was chosen such that $\sim 90$ per cent of the combined severe and significant sample were correctly classified, with the line being shifted in threshold value but parallel to the original relationship determined using the discriminant analysis.

$$
\text { CAPE } \times \text { SO6 } 6^{1.67} \geq 68000
$$

This results in three discriminants that can be applied to any set of climatological sounding data in order to determine the population of Significant Severe, Potentially Significant Severe (or Brooks et al.) and Severe Thunderstorm Environments (Fig. 7). It is noted that calibration of these discriminants is required depending on the source of environmental sounding profiles to cater for the variations in model resolution and rendering of convective variables. Further we acknowledge due to the relatively small sample size here that there remains some uncertainty within each of the discriminants, and hence caution should be taken in any results obtained by their application.
Fig. 7 Distribution of proximity soundings for severe thunderstorm reports (dots) and significant severe thunderstorm reports (red stars) in log(CAPE)-log(S06) phase space. Discriminant lines shown correspond to the discriminant determined (left to right) for severe thunderstorms from non-severe thunderstorms based on POD (Eq. 7, marked S), potentially significant severe thunderstorms (PSS) from severe thunderstorms which corresponds to a line drawn between the maximum and minimum variation lines (Eq. 6, marked PSS), and significant severe thunderstorms from severe thunderstorms (Eq. 4, marked Sig).

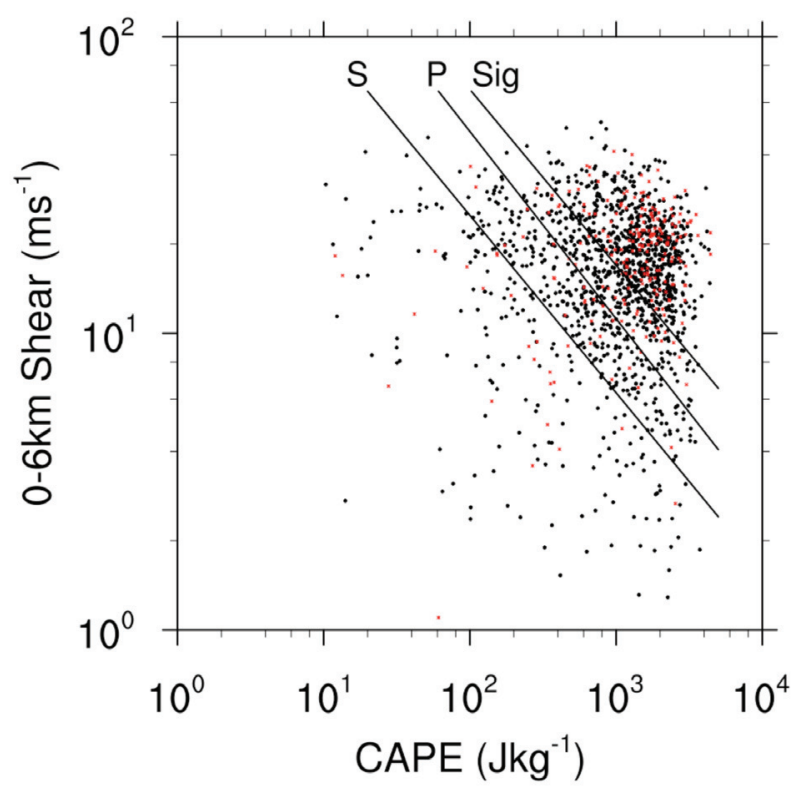

\section{Conclusion}

A unique and broad database of severe thunderstorm reports has been constructed for the Australian region for 2003-2010. Based on this database and the geographical distribution of both reports and radiosonde stations, an ingredients-based pseudo-proximity climatology was used to derive climatological discriminants for three different categories of severe thunderstorm events. This appears to be the best way to produce a long-term climatology of severe thunderstorm environments in a sparsely populated continent without considering the complex problem of initiation.

The MesoLAPS forecast data applied as the source of the proximity profiles displays some limitations when compared to radiosonde profiles. However, for the vast proportion of the Australian continent that is not coastal, there is little difference in model-derived shear (S06) compared to radiosonde soundings. In contrast CAPE suffers from significant issues with the spatial positioning of instability within the environment and coastal influences on the model profile. Applying a proximal radial area search for maximum CAPE seemed to help moderate this spatial difference between model and observed atmospheric profiles, although problems still remain in overestimation, particularly in low CAPE radiosonde environments. In coastal regions, care 
Table 4. POD for all Australian severe thunderstorm reports of both significant and severe categories, and POD for severe thunderstorm proximity soundings only for varying choices of constant while maintaining a slope equal to that of the significant severe/severe discriminant. The threshold chosen corresponds to a POD for all severe thunderstorm reports of 0.9

\begin{tabular}{lcc}
\hline Severe Threshold & POD & POD Severe \\
\hline 3.00 & 0.932 & 0.912 \\
3.10 & 0.911 & 0.890 \\
3.14 & 0.900 & 0.881 \\
3.20 & 0.866 & 0.843 \\
3.25 & 0.843 & 0.818 \\
3.30 & 0.818 & 0.791 \\
\hline
\end{tabular}

must be taken in any derived environments, where localized effects including seabreezes, orographic flows and the time of the unstable airmass may have a strong influence on the atmospheric profiles obtained. Particular attention should be paid to CAPE and the shear values derived from data in the lowest kilometre of the atmosphere, which appear to suffer most from these effects, with deep layer shear and the larger-scale system more likely to be rendered accurately.

The climatology of severe thunderstorm environmental profiles suggests that CAPE and S06 form two of the better indices for discriminating between severe and significant severe thunderstorm environments, with the locally applied forecasting quantity of LI500hPa being far more difficult to apply in this context. These profiles suggest that a large proportion of Australian severe thunderstorm environments are associated with an organized storm mode, with many of the environments meeting thresholds that would be considered favourable to supercells. However the distribution of these individual quantities do not adequately separate the two populations, and therefore a covariate remains a better solution.

The covariate discriminant determined using this climatology for Australia has been found to be similar to those applied in both the US and Europe, with these discriminants perhaps too low for this particular climatology. A linear discriminant has been determined tailored to Australian significant severe thunderstorms, with shear playing a marginally greater role. This results in a discriminant that considers a product of CAPE and S06 nearly squared, similar to the original Brooks et al. (2003) discriminant rather than the constant CAPE and 0-6 km shear product used as an approximation. The relatively small sample upon which the discriminant was based has been examined to determine its effect, and a 'grey area' of potentially significant severe events has been defined to encompass this uncertainty. Furthermore testing using ROC curves (not shown) suggests using the tailored discriminant makes significant gains, and this tailoring should be considered for any database used. Finally, a severe thunderstorm threshold has been determined despite the lack of a training null sample, using a POD threshold of 90 per cent. This can be used to estimate the population of severe thunderstorm environments in an extended climatological setting. The limitations of this set of discriminants include the potential bias associated with a relatively small sample of only seven warm seasons compared to the climatological period of interest, the problem of mis- or poorly sampled severe thunderstorm environments which are not reflective of the realized environment skewing the population distribution, and the model inadequacies in coastal locations, which may make the discriminant less reliable. There is also the potential that even if all the above are not an issue, the vast area of the Australian continent may yield a variety of different environments, and therefore the covariate discriminants may not be appropriate to all areas. In saying this, the physics of the convective process are common throughout the world, although synoptic frequency of these conditions occurring in a given location can vary greatly. This can result in distributions of ingredients that appear to differ, but may be similar if the frequency was not an issue. Whether this requires varying the discriminant used to determine these environments needs further examination. We also note that extreme drought conditions that have prevailed for six years of the climatology period may bias our sample and therefore the discriminants determined here.

Future work will include expansion of the pseudoproximity sounding approach for Australian severe thunderstorm environments to ERA-Interim reanalysis data. This will allow an assessment of the dependence of the discriminant on the spatial resolution of the soundings and application of the climatological discriminant to determine the evolution of Australian severe thunderstorm environments over the last twenty years and possible factors affecting their inter-annual variability.

\section{Acknowledgments}

We are grateful for the contributions of Dr Charles Doswell and one anonymous reviewer in improving the final manuscript. We also appreciate the suggestions and comments provided by Dr Harold Brooks in considering an earlier draft of this work. This research was supported in part by funding from the Australian Research Council Centre of Excellence for Climate System Science (grant CE 110001028).

\section{References}

Blanchard, D. 1998. Assessing the vertical distribution of convective available potential energy. Weath. Forecasting, 13, 870-877.

Brown, B.G. and Murphy, A.H. 1996. Verification of aircraft icing forecasts: the use of standard measures and meteorological covariates. Preprints, 13th Conf. Probability and Statistics in the Atmospheric Sciences, San Francisco, California, USA, Amer. Meteorol. Soc., 251-252.

Brooks, H., Doswell III, C. and Cooper, J. 1994. On the environments of tornadic and nontornadic mesocyclones. Weath. Forecasting, 9, 606618. 
Brooks, H., Lee, J. and Craven, J. 2003. The spatial distribution of severe thunderstorm and tornado environments from global reanalysis data Atmos. Res., 67, 73-94.

Brooks, H. and Dotzek, N. 2006. The spatial distribution of severe convective storms and an analysis of their secular changes. Climate Extremes and Society, Chapter 8, $24 \mathrm{pp}$.

Davis, S. and Walsh, K.J.E. 2008. Southeast Australian thunderstorms: are they increasing in frequency? Aust. Met. Mag., 57, 1-11.

Dean, A. and Schneider, R. 2008. Forecast challenges at the NWS Storm Prediction Centre relating to the frequency of favorable severe storm environments. Preprints, 24th Conference on Severe Local Storms, Savannah, GA, Amer. Meteor. Soc., 11 pp.

Deslandes, R., Richter, H. and Bannister, T. 2008. The end-to-end severe thunderstorm forecasting system in Australia: overview and training issues. Aust. Met. Mag., 57, 329-343.

Donaldson, R.J.Jr., Dyer R.M. and Kraus, M.J. 1975. An objective evaluator of techniques for predicting severe weather events. Preprints, 9th Conference on Severe Local Storms, Norman, OK, Amer. Meteor. Soc., 321-326.

Doswell III, C. and Rasmussen, E. 1994. The effect of neglecting the virtual temperature correction on CAPE calculations. Weath. Forecasting, 9 625-629.

Doswell III, C., Brooks, H. and Maddox, R. 1996. Flash flood forecasting: An ingredients-based methodology. Weath. Forecasting, 11, 560-581.

Doswell III, C., 2001. Severe convective storms, Chapter 1. Meteorological Monograph, Amer. Meteor. Soc., Boston, USA, 570 pp.

Doswell III, C., Brooks, H. and Kay, M. 2005. Climatological estimates of daily local nontornadic severe thunderstorm probability for the United States. Weath. Forecasting, 20, 577-595

Griffiths, D., Colquhoun, J. Batt, K. and Casinader, T. 1993. Severe thunderstorms in New South Wales: climatology and means of assessing the impact of climate change. Climatic Change, 25, 369-388.

Hales Jr, J. 1993. Biases in the severe thunderstorm database: Ramifications and solutions. Preprints, 13th Conf. on Weather Forecasting and Analysis, Vienna, VA, Amer. Meteor. Soc., 4 pp.

Harper, B., Granger, K. and Hall, S. 2001. Severe thunderstorm risks. Natural Hazards and the Risks they Pose to South-East Queensland, Aus. Geo. Surv. Organisation, 15 pp.

Kelly, D., Schaefer, J. and Doswell III, C. 1985. Climatology of non-tornadic severe thunderstorm events in the United States. Mon. Weath. Rev., 113, 1997-2014.

Knight, C.A. and Knight, N.C. 2001. Hailstorms. Severe Convective Storms, Meteorological Monographs, Chapter 6, Amer. Meteor. Soc. 28, 570 pp.

Kounkou, R., Mills, G. and Timbal, B. 2009. A reanalysis climatology of cool-season tornado environments over southern Australia. Int. J. Climatol., 29, 2079-2090.

Kuleshov, Y., de Hoedt, G., Wright, W. and Brewster, A. 2002. Thunderstorm distribution and frequency in Australia. Aust. Met. Mag., 51, 145-154.

Lee, J. 2002. Tornado proximity soundings from the NCEP/NCAR reanalysis data. Unpublished MS Thesis, University of Oklahoma, $61 \mathrm{pp}$

Marsh, P.T., Brooks, H.E. and Karoly, D.J. 2009. Preliminary investigation into the severe thunderstorm environment of Europe simulated by the Community Climate System Model 3. Atmos. Res., 93, 607-618.

Mills, G. and Colquhoun, J. 1998. Objective prediction of severe thunderstorm environments: Preliminary results linking a decision tree with an operational regional NWP model. Weath. Forecasting, 13, 1078-1092.

Mills, G. 2004. Verification of operational cool-season tornado threat-are forecasts from mesoscale NWP and a probabilistic forecast product. Aust. Met. Mag., 53, 269-277.

Niall, S. and Walsh, K. 2005. The impact of climate change on hailstorms in southeastern Australia. Int. J. Climatol., 25, 1933-1952.

Potvin, C., Elmore, K. and Weiss, S. 2010. Assessing the impacts of proximity sounding criteria on the climatology of significant tornado environments. Weath. Forecasting, 25, 921-930.

Puri, K., Dietachmayer, G., Mills, G., Davidson, N., Bowen, R. and Logan, L. 1998. The new BMRC limited area prediction system, LAPS. Aust. Met. Mag., 47, 203-223.

Rasmussen, E. and Blanchard, D. 1998. A baseline climatology of sound- ing-derived supercell and tornado forecast parameters. Weath. Forecasting, 13, 1148-1164.

Rasmussen, E. 2003. Refined supercell and tornado forecast parameters. Weath. Forecasting, 18, 530-535.

Riemann-Campe, K., Fraedrich, K. and Lunkeit, F. 2009. Global climatology of convective available potential Energy (CAPE) and convective inhibition (CIN) in ERA-40 reanalysis. Atmos. Res., 93, 534-545.

Ryan, C.J. 1992. Dynamical Classification of Australian Thunderstorms. BOM Meteor. Study, No. 40, Monash University, 61 pp.

Schaefer, J.T. 1990. The critical success index as an indicator of warning skill. Weath. Forecasting, 5, 570-575.

Schuster, S., Blong, R. and Speer, M. 2005. A hail climatology of the greater Sydney area and New South Wales, Australia. Int. J. Climatol., 25, 1633-1650.

Tailleux, R. and Grandpeix, J. 2001. A generalized Convective Inhibition Energy. Q. J. R. Meteorol. Soc., 30, 1-20.

Thompson, R., Edwards, R., Hart, J., Elmore, K. and Markowski, P. 2003. Close proximity soundings within supercell environments obtained from the Rapid Update Cycle. Weath. Forecasting, 18, 1243-1261.

Thompson, R., Mead, C. and Edwards, R. 2007. Effective storm-relative helicity and bulk shear in supercell thunderstorm environments. Weath. Forecasting, 22, 102-115.

Weisman, M. and Klemp, J. 1982. Dependence of numerically simulated storms on vertical wind shear and buoyancy. Mon. Weather Rev., 110, 504-520.

Wilks, D.S. 2006. Statistical Methods in the Atmospheric Sciences. 2nd Ed. International Geophysics Series, Vol. 59, Academic Press, 627 pp.

Yeo, S., Leigh, R. and Kuhnel, I. 1999. The April 1999 Sydney Hailstorm. Aust. J. Emer. Man., 14, 23-25. 


\section{University Library}

\section{- M M N E R VA A gateway to Melbourne's research publications}

Minerva Access is the Institutional Repository of The University of Melbourne

Author/s:

Allen, John Terrence;Karoly, David J.;Mills, Graham A.

Title:

A severe thunderstorm climatology for Australia and associated thunderstorm environments

Date:

2011

Citation:

Allen, J. T., Karoly, D. J., \& Mills, G. A. (2011). A severe thunderstorm climatology for Australia and associated thunderstorm environments. Australian Meteorological and Oceanographic Journal, 61(3), 143-158.

Publication Status:

Published

Persistent Link:

http://hdl.handle.net/11343/32768 